\section{Development of a longitudinal database for an integrated curriculum}

\author{
Linda R. Adkison, David L. Lockwood, \\ Andrea L. Hanson, Alan G. Glaros \\ Kansas City University of Medicine and \\ Biosciences, MO, USA
}

\section{Abstract}

Many medical schools have transitioned to an integrated curriculum to provide a more salient contextual appreciation of the practice of medicine. Various types of assessments are used in these curricula to support this integration. One of these, multidisciplinary exams, creates challenges for recognizing student performance in different disciplines. A concern for faculty is those students who pass the exams but upon closer scrutiny do poorly in one or more disciplines. Unfortunately, this trend can continue throughout preclinical training. We constructed a database of discipline-specific objective data for each course and that also provided cumulative data longitudinally through the curriculum. The data are used to populate reports for the students, advisors, and administrators. The database was broadened to include data from clerkship performance and residency match to provide a complete profile of student performance. Together, the data and reports provide a useful tool for student review and data-driven curriculum decisions.

\section{Background}

Many medical schools transitioned from discipline-driven curricula to various forms of integrated curricular during the past thirty years to better reflect patient presentations and improve learning outcomes. The Kansas City University of Medicine and Biosciences (Missouri, USA) curriculum is an integrated, patient-centered approach to basic and clinical sciences across the curriculum. The challenges faced by institutions to curricular change differed for students and faculty. ${ }^{1} \mathrm{~A}$ common theme among faculty was the concern about insufficient time to teach a discipline as effectively in an integrated curriculum as in an independent discipline course. ${ }^{2}$ To assess students in these curricula, many schools adopted multidisciplinary examinations but implementation of this format often left departments with less objective data about student outcomes. For example, a student might pass a course comprised of multiple disciplines but not necessarily done well in all disciplines. Providing timely, longitudinal, and comprehensive discipline data to faculty and students was challenging. A curricular goal is to insure a level of proficiency and competency, ${ }^{2,3}$ and yet such exams can make it difficult to track students who are persistently weak in one or more disciplines. This inability also makes it difficult for faculty to effectively evaluate student outcomes and make data-driven decisions about curriculum. Therefore, we developed a database to provide longitudinal disciplineand student-specific curricular data to improve the learning experience and curriculum.

The specific goals of this project were: i) to develop a database populated with objective assessment data for each student; ii) to create useful reports for individual students, faculty advisors, and department chairs; and iii) to produce useful reports for department chairs and faculty that would be available soon after finalizing section grades.

\section{Innovation}

Multidisciplinary examinations are developed to assess students' ability to think of the patient as a whole rather than as a collection of individual disciplines. The greatest amount of objective data is generated during the first two years of the curriculum. A database was developed to sort student performance information for exam questions that were tagged with disciplines tracked. From the exam software, data are imported from a macro developed for these tagged objective data. When imported, the data reside in tables and queries that populate the report fields automatically. It was developed first in Access for beta testing and then moved to SQL. Several views of the database with sample data are shown in the Appendix (Figure A1). Demographic and other student data are uploaded directly from PowerCampus (Ellucian), the ERP system utilized by the University. For security, distribution of reports to students and advisors (Appendix, Figure A2) is through Blackboard, the learning management system. These reports provide performance data by discipline for the recently completed section (or course) and also cumulatively to date. Distribution of de-identified reports to department chairs and other administrators provides information about individual (deidentified) and class performances in a section and cumulatively for each discipline (Appendix A3). Department chairs and administrators may request identified information for specific purposes. For example, an elective was created for a student cohort doing poorly in a discipline and these students were invited to enroll. A committee also monitors students with poor
Correspondence: Linda R. Adkison, Department of Genetics, Kansas City University of Medicine and Biosciences, 1750 Independence Avenue, Kansas City, MO 64106, USA.

Tel.: + 1.816.654.7312.

E-mail: ladkison@kcumb.edu

Key words: integrated curriculum, database, longitudinal tracking.

Contributions: the authors contributed equally.

Received for publication: 9 December 2013.

Revision received: 13 July 2014.

Accepted for publication: 31 July 2014.

This work is licensed under a Creative Commons Attribution NonCommercial 3.0 License (CC BYNC 3.0).

(C) Copyright L.R. Adkison et al., 2014

Licensee PAGEPress srl, Italy

Medical Education Development 2014; 4:5231

doi:10.4081/med.2014.5231

academic performance and identifies specific interventions to assist these students improve their performance.

The clinical training program is a distributed model over multiple sites and is coordinated by the University through regional assistant deans. Data from the second two years of the curriculum includes information such as clinical sites, shelf exams, and board performance for each clinical discipline. The database provides a single site for information to assess associations between clinical and preclinical performance by student, site, or clerkship in more detail than available on the transcript of grades. The usefulness of the database was extended to include post-graduate information such as residency match information for type of match (the American 0steopathic Association, A0A, or the Accreditation Council for Graduate Medical Education, ACGME), match status, site, specialty, and specialty status (categorical or preliminary). Included is information about secondary site or specialty, if applicable. This latter information will provide opportunities to perform outcomes analyses on the impact of curriculum on residency selection using many independent variables, such as preclinical and clinical discipline performance, national board discipline performance, and site of training.

The database is easy to manipulate to add fields. This feature allows consideration of other types of data such as competencies which schools are beginning to address along with cognitive proficiencies. ${ }^{4}$ Consideration is currently being given to including additional information about residency applications, such as additional sites and specialties to which the 
student applied. This information could be used to supplement information from the NMRP Program Director Survey and provide a better institutional understanding of trends within class cohorts. ${ }^{5}$ The database can be individualized to other institutions and is easy to transfer the template.

\section{Evaluation}

A survey of faculty showed the development of the advisor report was well-received. The survey used a Likert scoring scale and asked faculty to rate statements about the advisor's report and the chair report. Figure A4 (Appendix) shows $83 \%$ of faculty agreed or strongly agreed with statements about the advisors report. The most significant feature of the report was the inclusion of cumulative data. Students with persistent performance problems were not easily identified by advisors previously, and the report made it easier to address concerns during advising meetings. The most common recommendation from the faculty was to provide the reports sooner. Reports are presently completed within 7-10 days of finalization of grades for the section.

The report sent to the department chairs (Appendix, Figure A3) provided data stratified by deidentified individuals for each discipline and was available as either a .pdf file or Excel spreadsheet for departmental analyses. This serves two purposes. Faculty can view individual performances while at the same time view how their discipline did among other disciplines. Less than half (43\%) of the faculty were aware of the reports sent to the chairs to share with their faculty (Appendix, Figure A4). Approximately $26 \%$ of faculty agreed or strongly agreed that the report provides chairs and faculty more information about the department's performance than they have had previously; this underscores the need for improved communication with faculty. Comments suggest faculty are feeling information overload from the new reports. Because each class has 250 students, the available data for departments is significant. The availability of the spreadsheet should allow faculty to better sort and evaluate the information. With high stakes assessments, which represent the preponderance of assessments in our curriculum, it is important to focus on outcomes of our program at each step. ${ }^{6}$ Data have been used to review summative outcomes of disciplines and establish a benchmark of student accountability for discipline cognitive knowledge. As a result of these data and the ability to generate reports, minimal knowledge competencies for basic sciences disciplines have been established for students by the faculty. Minimal medical knowledge proficiency must be attained prior to the beginning of clerkship training.

\section{Conclusions}

The development of this database has centralized all objective student data that were difficult to view in an integrated curriculum previously. It includes longitudinal data for each student and post-graduate information. Data fields are easily populated with exam data and national reports that are imported and linked to tables and queries by student identification numbers. Editing fields can be accomplished easily to individualize reporting for institutions.

Creating reports has generated several medical education projects that would have been difficult prior to the database. However, careful consideration of the purpose of a report and the action of possible outcomes is recommended. In addition to reports for faculty and students, the database is becoming a portfolio of student information beyond its original purpose and will include information currently housed in other areas of the University such as publications, presentations, and scholarships.

\section{References}

1. Muller JH, Jain S, Loeser H, Irby DM. Lessons learned about integrating a medical school curriculum: perceptions of students, faculty, and curriculum leaders. Med Edu 2008;42:778-85.

2. Nazian SJ, Stevenson FT. The use of horizontal basic science proficiencies in a systems based curriculum. Med Sci Edu 2013;23:2-5.

3. Wilkerson L, Stevens CM, Krasne S. No content without context: integrating basic, clinical, and social sciences in a pre-clerkship curriculum. Med Teach 2009;31:812-21.

4. Kerdijk W, Snoek JW, van Hell EA, CohenSchotanus J. The effect of implementing undergraduate competency-based medical education on students' knowledge acquisition, clinical performance and perceived preparedness for practice: a comparative study. BMC Med Edu 2013;13:76.

5. National Resident Matching Program, Data Release and Research Committee. Results of the 2013 NRMP applicant survey by preferred specialty and applicant type. Washington, DC, 2013. Available from: h t t p ://b 83 c 73 b c f 0 e 7 c a 356 c 80 e8560f466940e4ec38ed51af32994bc6.r6.cf 1.rackcdn.com/wp-content/uploads/ 2013/08/applicantresultsbyspecialty2013.p df. Accessed on: July 2014.

6. Schuwirth LWT, van der Vleuten CPM. General overview of the theories used in assessment: AMEE Guide No. 57. Med Teach 2011;33:783-97. 